\title{
Educação ambiental e a agroecologia: uma prática inovadora no processo educativo no educandario aprendendo a aprender, Bananeiras - PB
}

Environmental Education and Agroecology: an innovative practice in the educational process at Educandário learning to learn, Bananeiras - PB

\author{
Adailza Guilherme da Silva', Maria José Ramos da Silva², \\ Alian Cássio Pereira Cavalcante ${ }^{3}$, Belísia Lúcia Moreira Toscano de Diniz ${ }^{4}$ \\ I, 2, 3, ${ }^{4}$ Universidade Federal da Paraíba, Campus III, Bananeiras-PB
}

\section{Resumo}

A educação ambiental é o principal instrumento para moldar esta nova forma de ver e de sentir o mundo ao nosso redor. Desta forma objetivou- se trabalhar a educação ambiental e a agroecologia de forma precisa, enfatizando o lixo como um dos principais problemas ambientais da atualidade através da sensibilização dos educandos. O trabalho foi realizado no Educandário Aprendendo a Aprender, na turma do $5^{\circ}$ ano do ensino fundamental, consistindo na exposição de aulas teórica, evidenciando o uso de dinâmicas, seguida de práticas com oficinas de reciclagem, e aplicação de questionários semiestruturado. Constatou-se que a educação ambiental e a agroecologia é hoje o instrumento eficaz e necessário para a sensibilização dos educandos, permitindo criar e aplicar formas sustentáveis de interações com a natureza. Esta possibilitou a visualização do nível de conhecimentos dos entrevistados e seu posterior compromisso com os recursos ambientais.

Palavras-chave: Educação, Espaço Escolarizado, Recursos Ambientais

\begin{abstract}
Environmental education is the main instrument to shape this new form of see and feel the world around us. Thus the objective was to work on environmental education and agroecology of accurate, emphasizing the trash as one of the main environmental problems of today by raising awareness among students. The study was conducted in breed Learning to Learn, in the class $5^{\circ}$ year of elementary school, consisting of the exposure classes theoretical, showing the use of dynamic followed by practical workshops with recycling, and semi-structured questionnaires. It was found that environmental education and agroecology today is effective and necessary for the awareness of students, allowing you to create and implement sustainable forms of interactions with nature. This allowed visualization of the level of knowledge of respondents and their subsequent commitment to environmental resources.
\end{abstract}

Keywords: Education, Space schooled, Environmental Resources 


\section{INTRODUÇÃO}

No século XIX, o homem começou a explorar e dominar a natureza de forma irracional, aliada ao crescente processo de industrialização. Com isso, o desenvolvimento passou a ser visto como sinônimo de progresso. No entanto, a exploração desenfreada da natureza culminou em inúmeras agressões ao meio ambiente tornando-se bem expressivos nos últimos anos.

A utilização dos recursos ambientais pelo homem é uma prática antiga, sendo sinônimo de sobrevivência, principalmente nos primórdios da existência em que o mesmo retirava o seu sustento da floresta, no entanto, na ocasião era coletado apenas o necessário sem interferir de forma agressiva no ecossistema, entretanto a maneira de maneja-los que vem sendo modificado a cada geração.

Para Aresi e Manica (2010), a rápida transformação do ambiente provocada pelo homem não obedeceu às leis de conservação da natureza e sim as leis econômicas. Buscamos modificar de forma útil à matéria prima fornecida pela natureza, para nosso próprio bem estar, desenvolvendo um processo de interação entre homem/natureza, mas esse processo desencadeia uma relação desigual, pois acabamos por modificar de forma significativa o ambiente em que estamos inseridos.

Em contraposição a esse modelo, surge a agroecologia que visa um equilíbrio nas relações do homem com a natureza, evidenciando sempre o natural em uma lógica em que a natureza mostra o caminho, como por exemplo, o ato de trabalhar dentro do meio ambiente, preservando-o, visando o equilíbrio entre os nutrientes, o solo, a planta, a água e os animais, e continuar extraindo alimentos da terra sem esgotar os recursos ambientais e sem destruir o meio ambiente (CAPORAL; COSTABEBER, 2004).

Nesta perspectiva, faz-se necessário introduzir práticas ambientais nas escolas e no meio social a fim de provocar nas pessoas atitudes menos agressivas ao meio ambiente, que promova a inclusão social e proporcionem melhores condições econômicas. Para Pereira (2007), a falta de sensibilização da população é um forte agravante deste fato. Desta forma, é essencial a introdução de práticas que reflitam na formação e proporcione uma posterior sensibilização dos educandos nas fases inicias do ensino, ou seja, na educação básica. A mesma torna-se de extrema necessidade para a sobrevivência do homem na terra.

A Organização das Nações Unidas reco- nhece que o ensino deve ser entendido como um processo pelo qual os seres humanos e as sociedades podem desenvolver plenamente suas potencialidades e aumentar suas capacidades em abordar questões sócio-ambientais relacionadas ao desenvolvimento sustentável. Para isso, deve afirmar valores e ações que contribuam com a transformação humana e social e com a preservação ecológica (ONU, 1992).

A adoção de práticas mais amigáveis com a natureza requer mudanças, transformações e novos comportamentos. Diante disso, não podemos deixar de inserir a educação ambiental quando falamos em agroecologia, pois ambas surgem da necessidade de mudanças, adoção de novos estilos de vida que tragam melhor qualidade de vida, conservação da biodiversidade e geração de trabalho, em um sistema econômico mais justo (CRIVELLARO, et al. 2008).

Segundo Dias (2004), a educação ambiental é o principal instrumento para moldar esta nova forma de ver e de sentir o mundo ao nosso redor, pois constitui elementos integradores nos sistemas educativos dentro de uma sociedade para fazer com que a comunidade tome consciência do fenômeno do desenvolvimento sustentável e de seus efeitos ambientais. Diante disso, é necessário o conhecimento acerca da manipulação dos resíduos que são produzidos diariamente e o que fazer para minimizar esse efeito ao ambiente, sendo-a a reciclagem a prática mais difundida.

A referente deve proporcionar experiências que possibilitem colocar as pessoas em contato direto com o mundo e sensibilizá-las para os ecossistemas que as envolvem; discutir a importância do ambiente para a saúde e o bem estar do homem e para o exercício da cidadania; avaliar o desenvolvimento econômico aliado à degradação ambiental e à qualidade de vida e desenvolver no educando o sentido ético-social diante dos problemas ambientais.

O trabalho justifica-se pelo fato de que o meio ambiente é um tema transversal dos Parâmetros Curriculares Nacionais (PCNs), buscando suportes metodológicos de atividades educativas por isso as ações de Educação Ambiental e a Agroecologia procuram informar, orientar e sensibilizar a população sobre os recursos ambientais.

Desta forma, objetivou- se trabalhar a educação ambiental e a agroecologia de forma precisa, enfatizando o lixo como um dos principais problemas ambientais da atualidade através da sensibilização dos educandos. 


\section{REFERENCIAL BIBLIOGRÁFICO}

\section{I Educação ambiental nas escolas}

Por entender que a escola é uma das responsáveis pela formação de cidadãos conscientes dos seus direitos e deveres, faz necessário a inserção de tema interdisciplinar que muitas às vezes não são contempladas nos currículos escolares.

Segundo Morgenstern e Francischett (2008), a escola efetiva-se como espaço formador de agentes de mudanças, visto que, é um ambiente propício à formação de novas atitudes, de novos comportamentos e valores.

Daí a importância de trabalhar desde cedo as questões ambientais no ensino formal, sendo integrada ao currículo de forma a promover uma melhor aprendizagem e despertar a sensibilização do educando, contextualizando com a sua realidade na formação do cidadão crítico e participativo (BRASIL, 2004).

Nessa conjuntura, a Educação Ambiental (EA) é um processo de aprendizado que busca despertar uma consciência crítica sobre a postura do homem em relação aos recursos ambientais. Para isso, é coerente informar e sensibilizar as pessoas sobre os problemas ambientais e suas possíveis soluções, buscando transformar os indivíduos em participantes ativos das decisões de sua comunidade.

Hoje as práticas de educação ambiental estão sendo expostas de muitas maneiras como, por exemplo, educação ambiental popular, crítica, política, comunitária, formal, não formal, para o desenvolvimento sustentável, conservacionista, socioambiental, ao ar livre, para solução de problemas. Percebe-se que a educação ambiental disponibiliza uma diversidade de práticas para a formação dos sujeitos (LAYRARGUES, 2004).

Conforme Reigota (1994), existem muitos métodos para a realização da educação ambiental, mas o mais adequado é que cada professor seja capaz de estabelecer o seu, e que o mesmo venha a encontro da realidade dos seus educandos.

$\mathrm{Na}$ tarefa de ensinar, é necessário a inserção do professor na realidade do aluno, para que haja troca de experiências. Segundo Freire (2000, p. 25) "Quem ensina aprende ao ensinar e quem aprende ensina ao aprender".

Conforme Freire (2000, p. 52) é preciso "saber que ensinar não é transferir conhecimentos, mas criar as possibilidades para a sua própria produção ou as suas construções". Diante disso torna-se incoerente no processo de ensino utilizar conteúdos que às vezes estão muito além de nossos próprios conhecimentos, o que leva a um desinteresse por assuntos que estão ao nosso redor, e que cabe a nós a mudança para os mesmos.

\subsection{Conservação dos recursos ambientais através da agroecologia}

A prática da agricultura por si só causa perda ao meio ambiente, mas quando é feita de forma que visem à preservação dos recursos ambientais ocorre à minimização desses danos. Só que com o advento da modernização dos sistemas produtivos foram desconsiderados os elementos ambientais e evidenciado apenas os fatores de produção o que culminou para o esgotamento de alguns recursos ambientais como também a extinção de diversos seres vivos que constituem a natureza.

Em contrapartida a este sistema produtivo vários setores da sociedade vêm incentivando a buscar por estilos de agricultura menos agressivos ao meio ambiente, capazes de proteger os recursos ambientais e que sejam duráveis no tempo, tentando fugir do estilo convencional de agricultura.

Neste ambiente de busca e construção de novos conhecimentos, nasceu a Agroecologia, como um novo enfoque científico, capaz de dar suporte a uma transição a estilos de agriculturas sustentáveis e, portanto, contribuir para o estabelecimento de processos de desenvolvimento rural sustentável (CARPORAL; COSTABEBER, 2004).

Para Gliessman (2000), o enfoque agroecológico pode ser definido como "a aplicação dos princípios e conceitos da Ecologia no manejo e desenho de agroecossistemas sustentáveis", num horizonte temporal, partindo do conhecimento local que, integrando ao conhecimento científico, dará lugar à construção e expansão de novos saberes socioambientais, alimentando assim, permanentemente, o processo de transição agroecológica.

A agroecologia não implica apenas na busca de uma maior racionalização econômico -produtiva, com base nas especificidades locais de cada agroecossistemas, mas também numa mudança nas atitudes e valores dos atores sociais em relação ao manejo e conservação dos recursos ambientais. (GLIESSMAN, 2000).

Nesta perspectiva, a sociedade no geral é instigada a introduzir no seu dia-a-dia pequenos gestos, como não jogar lixo nas ruas, não polui os rios, açudes, não deixar a torneira ligada, evitar o 
desperdício de alimentos no intuito de termos uma melhor qualidade de vida e consequentemente uma sociedade mais justa e igualitária tanto ecologicamente quanto economicamente e socialmente.

\subsection{Consequências do descarte incorreto do lixo}

Com o crescimento da população houve um acrescimento no consumo e posterior acúmulo de resíduos domésticos e industriais (QUEIROZ, 2008). O acúmulo do lixo nas cidades é, sem dúvida, um dos grandes problemas ambientais da atualidade em virtude do consumo exacerbado das pessoas que buscam sempre seguir as tendências do mercado.

Mais cabe a sociedade refletir o que vem a ser o lixo. O mesmo é decorrência da atividade humana, visto que em processos da própria natureza toda sobra ou resíduo será reaproveitada. Por tanto os resíduos orgânicos (restos de frutas, legumes e de alimentos em geral), podem ser reciclados através do processo de compostagem. Cerca de $60 \%$ do lixo domiciliar produzido no país é constituído de matéria orgânica podendo ser tratada e transformada em adubo (humificados) para o uso agrícola (PEREIRA NETO, 2011).

Segundo Rosa et al. (2005), a reciclagem é o resultado de uma série de atividades pelas quais materiais que se tornariam descartáveis, ou estão descartados, coletados, separados e processados para serem usados como matéria-prima na manufatura de novos produtos. Este é, atualmente, a forma mais viável para a minimização dos problemas provenientes do lixo, contribuindo para o desenvolvimento sustentável.

Entretanto a reciclagem é pouco praticada, sendo mais comum encontrar aterro e lixão a céu aberto o que propicia um risco incalculável a sociedade no desenvolvimento e a proliferação de roedores, insetos e outros vetores de doenças, além de promover a contaminação dos solos, da água e poluição do ar (ALENCAR, 2005). Entretanto, a reutilização e o incentivo a reciclagem são práticas que além de preservar o meio ambiente gera uma renda extra e nas cidades do país, empregos para os cidadãos que catam e vende o lixo para as empresas de reciclagem, na qual muitas indústrias reciclam os materiais para reduzir os custos de produção evitando que uma parcela dos resíduos produzidos seja lançada nos aterro (SILVA; CAVALCANTE e SILVA, 2012).

O processo físico-químico de decomposição dos resíduos orgânicos, se não controlado de forma correta, irá produzir líquidos percolados (chorume), em sua maioria rica em metais pesados, chumbo, níquel, cádmio, dentre outros, que contaminam os veios hídricos e cursos d'água quando infiltrados no solo (BIDONE; POVINELLI, 1999).

É valido evidenciar o tempo de decomposição de alguns objetos que levam anos para serem transformados e em alguns casos pode- se evitar tais transtornos ao meio ambiente com práticas diárias simples, como: reduzir, reutilizar e reciclar (conceito dos três Rs). A partir desses princípios, o cidadão deve aprender a reduzir o lixo gerado, reutilizar sempre que possível os materiais antes de descartá-los e, só por último, pensar na reciclagem dos materiais (SOARES, 2007).

Para Alencar (2005), um enfretamento a esta situação deve partir da escola que tem um papel significativo na formação dos indivíduos, na sua cultura, nas suas relações sociais, e por ser difusora de conhecimentos e formadora de opiniões, deve abordar e apresentar meios simples e práticos para enfrentar o problema do lixo através do desenvolvimento de atividades que propiciem reflexões, participação e, acima de tudo, comprometimento pessoal e mudança de atitudes para com a natureza.

\section{METODOLOGIA}

O trabalho foi realizado no Educandário Aprendendo a Aprender localizada no distrito de Roma, Bananeiras PB. As visitas ocorreram semanalmente com uma turma do $5^{\circ}$ ano do ensino fundamental.

Inicialmente, apresentou-se o projeto aos educandos e educadores da respectiva escola, aos quais foram expostos os temas e as metodologias das aulas, esse momento permitiu a interação do público envolvido para fazer as suas colocações e sugestões de acordo com as concepções e necessidades curriculares. A metodologia utilizada baseou-se em trabalho realizado por LELIS et al, (2007), que utilizaram métodos participativos que valorizam o diálogo, as vivências cotidianas e o conhecimento de cada educando, estimulando a existência de uma relação mais interativa e afetiva entre os facilitadores e os educandos.

Considera-se essencial a participação dos educandos na construção do currículo escolar tendo em vista que são eles os principais atores nesse processo. Diante disto os conteúdos abordados 
foram: O lixo, as suas causas e consequências; O solo e sua importância para o meio ambiente; Problemas ambientais: queimadas, poluição do solo e água; erosão e preservação do meio ambiente através da agroecologia.

Consistiu-se na exposição de aulas teórico -práticas e dinâmicas, a fim de estimular a expressão oral e escrita dos educandos destacando-se as oficinas de reciclagem, cartazes, atividade de formação do perfil do solo, apresentação de vídeos. Os materiais utilizados nas oficinas de reciclagem foram: cola, caneta, cartolinas, lápis de cor, lápis grafite, tesouras e borrachas, CDs, DVDs, garrafa PET, papelão, tampinha de garrafas, metal, retalhos de tecidos e palito de churrasco, ambos trazidos pelos próprios alunos. Essa estratégia permitiu a reutilização de objetos que eram considerados sem utilidade pelos educandos e minimizar os danos que poderiam causar quando exposto no meio ambiente de forma inadequada.

Foi priorizada durante as aulas a aplicação de dinâmicas, por entender que o sucesso de uma boa aula está relacionado também com a utilização de novas estratégias educacionais participativas, estimulam a curiosidade, são lúdicas, descontraem o ambiente e favorecem o trabalho em grupo entre os educandos

Ao término de cada aula foi realizada uma breve caracterização da percepção dos educandos com a aplicação de questionários semiestruturado a cerca dos conteúdos trabalhados tanto no diálogo em sala de aula, quanto na produção de cartazes. Essa dinâmica de trabalho permitiu visualizar o nível de entendimento e compreensão dos educandos diante das aulas.

Após a aplicação do questionário, seguiuse a etapa de análise dos dados obtidos durante a pesquisa. Buscou-se dessa forma, distribuir graficamente em termos quantitativos os resultados das respostas do questionário, semelhante a analise quantitativa realizada por (SARAIVA; NASCIMENTO; COSTA, 2008).

\section{RESULTADOS E DISCUSSÕES}

Diante dos dados analisados contidos nos questionários com o auxilio do excel, foi possível analisar a percepção dos educandos em relação aos temas abordados.

$\mathrm{Na}$ figura 1, É mostrado o entendimento dos entrevistados sobre o que seria lixo e destes, $62 \%$ definiram como tudo o que utilizamos para fazer novos produtos; $23 \%$ afirmam que é tudo o que é descartado e não tem utilidade e $15 \%$ tudo o que jogamos no meio ambiente.

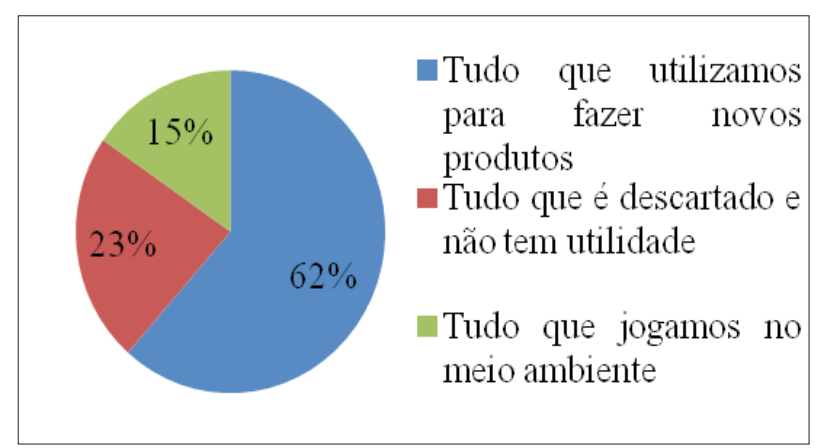

Figura 1. Percepção dos entrevistados sobre o que é lixo

Para os entrevistados, lixo é tudo o que não serve para mais nada e para mais ninguém, no entanto, muitas coisas que são descartadas ou jogadas fora por uma pessoa ainda podem servir para outra, dessa forma não são lixo e sim resíduos. Para Queiroz, Lima e Oliveira (2008), um agravante nesse processo é o consumo exacerbado das pessoas que buscam sempre seguir as tendências do mercado. Segundo estimativas, cada habitante produz em média, cerca de $1 \mathrm{Kg}$ de lixo diariamente, ou seja, se contabilizar-nos tudo isso, chegaria a milhões de toneladas de lixo produzidas anualmente. Produtos estes que vêm sendo depositados em lixões, em cursos de água ou terrenos baldios.

Quando questionados acerca do que polui a água e o solo (figura 2), $50 \%$ acredita que seja o lixo o principal responsável, $22 \%$ as queimadas, $21 \%$ os esgotos e $7 \%$ o uso de agrotóxicos na agricultura. Isso mostra que os entrevistados tem consciência dos danos causados pelos itens citados anteriormente.

Resultados semelhantes foram encontrados em trabalhos desenvolvidos por Santos (2007) onde $55 \%$ dos entrevistados apontaram o acúmulo de lixo como o mais preocupante problema ambiental. Para Castro (2008), a produção desordenada de lixo tem sido um grande problema que afeta, não só o meio ambiente, mas também pessoas, animais e plantas. Faz-se necessário que o ser humano, no uso de sua plena racionalidade, procurem alternativas mais lógicas e efetivas para tratar, reaproveitar, minimizar ou até eliminar a geração de resíduos. 


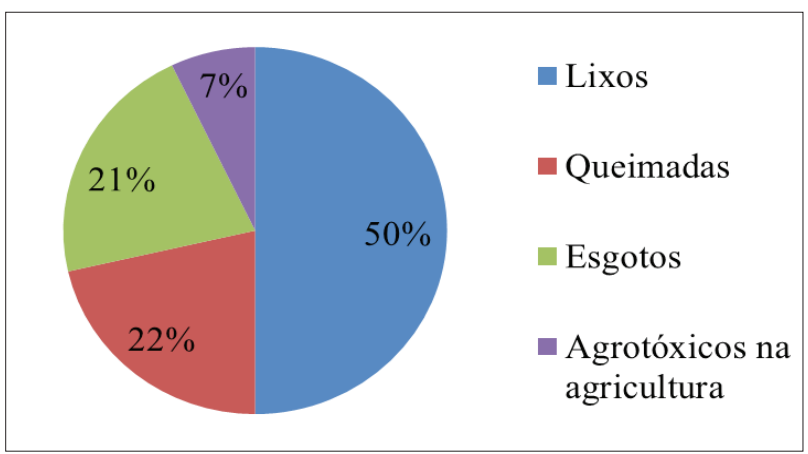

Figura 2. Poluidores da água e do solo

Considera-se necessário o conhecimento a cerca do tempo que vários materiais levam para se decompor, quando exposto ao meio ambiente, uma forma de comprometer as pessoas de suas responsabilidades diante dos recursos naturais. A figura 3 mostra a percepção dos educandos em relação a esse fato. Dos entrevistados, $64 \%$ afirmam que os resíduos orgânicos apresentam um menor tempo para serem decompostos, $29 \%$ acreditam que seja o papel pelo seu aspecto maleável e 7\% considera o metal de rápida decomposição.

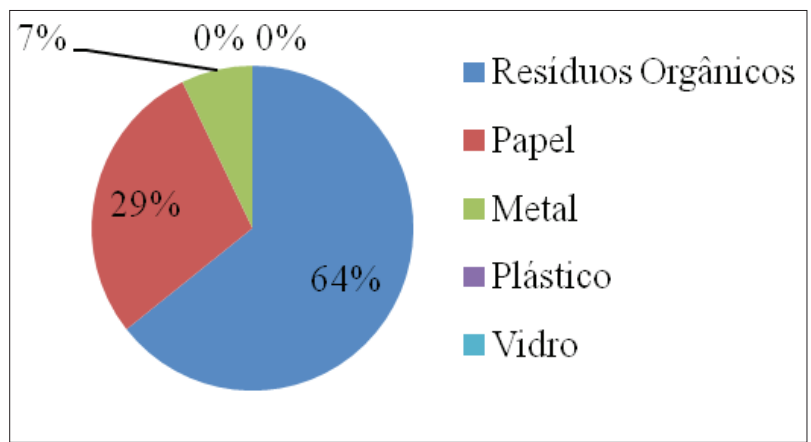

Figura 3. Percepção dos entrevistados acerca do tempo de decomposição dos materiais

Nota-se que existe uma deficiência dos educandos em relação a essa classificação sendo necessário proporcionar situação que desperte nele a sensibilização e aprendizagem.

As agressões que o meio ambiente vem apresentando desde a poluição de um pequeno açude até questões mais graves que desestrutura toda uma comunidade. Diante disso considerou-se pertinente perguntar aos entrevistados o que seria coleta seletiva de acordo com suas percepções e vivência, sendo que $77 \%$ foram simples e objetivo afirmando que consiste em separar o lixo de acordo com o material para reciclar, $15 \%$ acredita que seja o ato de coletar o lixo e levar para o lixão e os demais $8 \%$ responderam que é o fato de jogar o lixo todo misturado no meio ambiente (Figura 4).

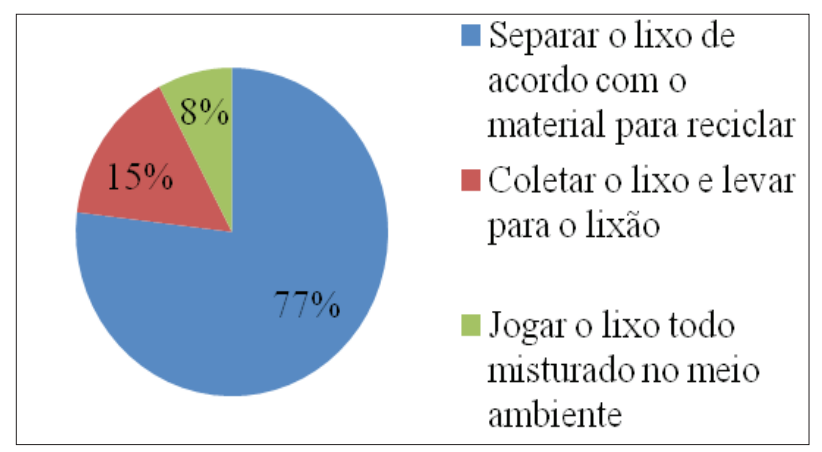

Figura 4. Percepção dos entrevistados acerca do que é coleta seletiva

Esse questionamento feito aos educandos remete que o fato do lixo ser jogado a céu aberto não estar relacionando a falta de informação em relação ao seu destino correto mais sim ao descompromisso das pessoas com os recursos ambientais, ou melhor, com a vida, não se sentem responsáveis, muitas vezes passando a responsabilidade apenas para os gestores públicos que tem o seu papel neste contexto também, mais é necessário haver a interação dos gestores juntos a sociedade civil. Segundo dados divulgados pelo Instituto Brasileiro de Geografia e Estatística (IBGE), por meio da Pesquisa Nacional de Saneamento Básico (2008), 18\% dos municípios brasileiros realizaram coleta seletiva.

É de conhecimento de todos os entrevistados que para haver a reciclagem se faz necessário haver a coleta seletiva que é uma etapa muito dispendiosa e muitas às vezes é considerada o fator limitante para tal. Nesse aspecto, a saída mais viável seria a seleção do lixo pelas próprias famílias, mais para isso é evidente ter conhecimento para diferenciar o lixo orgânico do inorgânico (Figura 5).

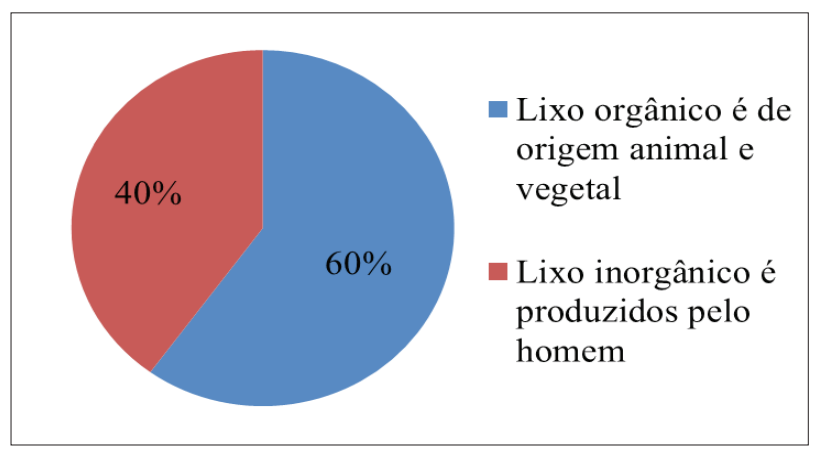

Figura 5. Lixo orgânico e inorgânico

No entanto, com esta pesquisa perceber-se que as pessoas fazem confusão em relação a essas categorias. Dos entrevistados, $60 \%$ acertaram ao responderem que o lixo orgânico é proveniente de resíduos de origem animal e vegetal e os demais 
$40 \%$ acredita que seja o lixo oriundo do meio humano. Para Soares (2007), pode-se minimizar os danos proveniente do lixo orgânico e inorgânico, apenas com a redução do lixo gerado, reutilizar sempre que possível os materiais antes de descartá-los.

Neste contexto, é primordial elencar a importância da agroecologia nesse processo de formação e aprimoramento de técnicas que visem preservar os recursos naturais, pois segundo Gliessman (2000) a agroecologia não implica apenas na busca de uma maior racionalização na produção, mas também uma mudança nas atitudes e valores dos atores sociais em relação ao manejo e conservação dos recursos ambientais.

Por isso, quando questionando os entrevistados acerca dos benefícios da agroecologia para os recursos ambientais, em especial o solo, $61 \%$ consideram bom, pois permite que as plantas se desenvolvam e produzam alimentos de qualidade, $23 \%$ não responderam $8 \%$ consideram bom pelo fato de fornecer cobertura ao solo para proteger contra o uso de agrotóxicos e os demais $8 \%$ atribuir os seus benefícios a produção de alimentos saudáveis (Figura 6).

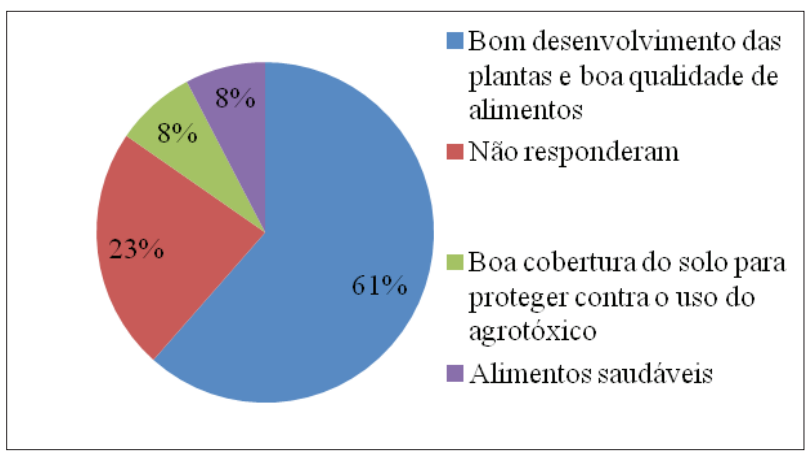

Figura 6. Percepção dos entrevistados acerca dos benefícios da agroecologia para os recursos ambientais

E notório que os entrevistados não têm clareza do que vem a ser agroecologia e quais as suas práticas e princípios para o meio ambiente e para a sociedade. Esse resultado pode estar relacionado ao fato da agroecologia ser uma ciência em construção com características transdisciplinares integrando conhecimentos de diversas outras ciências e incorporando inclusive, o conhecimento tradicional (FEIDEN, 2005).

Paralelo a esta observação foi estimulado aos alunos a fazer um levantamento acerca do que eles encontravam de sua residência até a escola (Tabela 1).
Tabela 1. Pontos positivos e negativos observados pelos alunos na caminhada ecológica de sua residência a escola na comunidade Roma, município de Bananeiras-PB, no ano de 2012

\section{POSITIVOS}

Plantas

Animais

Resíduos orgânicos

Lagos

Rios

Transformar resto de comida em resíduo orgânico

\section{NEGATIVOS}

Esgotos

Desmatamentos

Lixo

Queimadas

Poluição

Árvores derrubadas

Lixo nas ruas

Sacos de pipoca

Papel jogado no chão

Carros soltando fumaça
Após as oficinas ministradas, os alunos revelaram a preocupação com os problemas ambientais vivenciados pela sua comunidade, consequências estas advindas das atitudes irracionais do próprio homem para com a natureza. Através desse quadro foi possível perceber que os alunos têm conhecimento dos processos que culmina para uma educação ambiental consciente de seus diretos e deveres enquanto cidadãos.

Em trabalhos desenvolvidos por Silva et al (2011) na escola municipal Santos Dumont, Cáceres - MT, destacaram também como pontos positivos: pássaros, flores, plantas, bichos e rios e como pontos negativos destacaram: queimadas, poluição, árvores derrubadas, esgotos e lixo nas ruas, isso mostra a frequência dos problemas ambientais independente da região.

A educação ambiental desperta nas pessoas mudanças de comportamento que não se refere só à natureza, mas, a todo local onde estão inseridos, que ocorre num processo de aprendizagem permanente a todas as formas de vida (Quadro 1). 
Quadro 1. Retrata possíveis atitudes que minimiza os danos ao meio ambiente na comunidade Roma, município de Bananeiras-PB, no ano de 2012.

\section{PRÁTICAS PARA COMBATER A POLUIÇÃO DO ENTREVISTADOS SOLO E DA ÁGUA}

Redução da produção do lixo

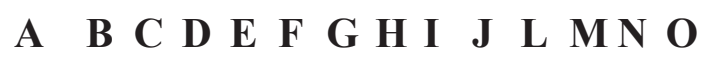

Uso de agrotóxicos nas plantas

Destino e tratamento adequado do lixo

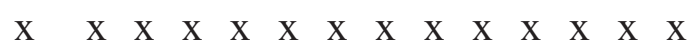

Reciclagem

$\begin{array}{lllllllllllllllll} & X & X & X & X & X & X & X & X & X & X & X & X & X & X\end{array}$

Jogar lixo no solo

Saneamento ambiental

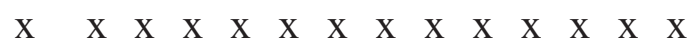

Produzir muito lixo

Métodos agrícolas que possam substituir os agrotóxicos $\mathrm{x}$

$\begin{array}{lllllllllll}X & X & X & X & X & X & X & X & X & X & X\end{array}$

Todos os entrevistados consideram práticas de grande relevância, a redução da produção do lixo, o destino e tratamento adequado do lixo, reciclagem, saneamento ambiental e $85,71 \%$ dos entrevistados consideram importante o uso de diferentes métodos agrícolas que possam substituir os agrotóxicos para a preservação do meio ambiente e os demais não corroboram com esses ideais e princípios ecológicos.

\section{CONSIDERAÇÕES FINAIS}

Através desse trabalho foi possível perceber o nível de conhecimentos dos entrevistados e seu posterior compromisso com os recursos ambientais. Considera-se que os problemas ambientais oriundos da ação humana ameaçam o equilíbrio natural do planeta e precisam ser combatidos e amenizados para que se possa garantir a preservação e manutenção dos recursos ambientais, e, sobretudo a sobrevivência da diversidade existente no nosso planeta. A educação ambiental trabalhada no cotidiano escolar, o que representa uma forma de ensinar os alunos que a preservação do planeta, bem como a diversidade biológica existente no mesmo, é um dever de todos os cidadãos.

Diante disso é necessário trabalhar em sala de aula conteúdos transdisciplinares para incluir tema relevante para a formação de cidadãos conscientes. Sendo essencial iniciar esse processo de formação nas séries iniciais, pois permite o primeiro contanto dos educandos com o meio ambiente.
Do ponto de vista educativo, o trabalho possibilitou o desenvolver a sensibilização nos alunos ao aliar o conhecimento teórico com o prático no estudo do meio, do qual o educando está habituado. Desta forma, os conhecimentos educativos ganharam mais significado e os alunos sentiram-se mais motivados e interessados por temas relacionados ao meio ambiente, principalmente no espaço sócio/natural em que os mesmos estão inseridos.

\section{AGRADECIMENTOS}

À equipe gestora, professores e alunos do Educandário Aprendendo a Aprender do distrito de Roma, Bananeiras-PB, que foram essenciais na colaboração para a efetivação deste trabalho.

\section{REFERÊNCIAS}

ARESI, D., MANICA, K. Educação ambiental nas escolas públicas: realidade e desafios. Monografia apresentada a Universidade Comunitária da região de Chapecó - curso de Ciências Biológicas. Chapecó - SC, 2010.

ALENCAR, M. M. M. Reciclagem de lixo numa escola pública do município de Salvador. Revista Virtual, Candombá, v. 1, n. 2, p. $96-113,2005$. 
BIDONE, F. R. A.; POVINELLI, J. Conceito básico de resíduos sólidos. São Carlos: EESC / USP, 1999.

BRASIL. Fundação Nacional de Saúde. Manual de Saneamento. 3. ed. Brasília: FUNASA, 2004.

CAPORAL, F. R., COSTABEBER, J. A. Agroecologia: alguns conceitos e princípios. MDA/SAF/ DATER-IICA, Brasília, p.24, 2004.

CASTRO, M. A. A reciclagem no contexto escolar. Disponível em: <http://www.diaadiaeducacao. pr.gov.br/portals/pde/arquivos/448-4.pdf>. Acesso em: 25 abr. 2013, 20:10:05.

CRIVELLARO, C. V. L.; CASTELL, C. H. G. P.; SILVEIRA, I. M. L.; SILVA, K. G.; CARVALHO, R V.; GROSSKOPF, T. A. C.; Núcleo de Educação e Monitoramento Ambiental, Agroecologia: um caminho amigável de conservação da natureza e valorização da vida, Rio Grande, p. 28, 2008.

DIAS, G. F. Educação ambiental: princípios e práticas. São Paulo: Gaia, 2004.

FREIRE, P. Pedagogia da Autonomia. 15. ed. São Paulo: Paz e Terra, 2000.

FEIDEN, A. Agroecologia: Introdução e Conceitos. In: AQUINO, A. M.; ASSIS, R. L. Agroecologia: Princípios e Técnicas para uma agricultura orgânica sustentável. (ed. téc.) $1^{\mathrm{a}} \mathrm{Ed}$. Brasília, DF. Embrapa Informação Tecnológica, 2005. p. 51-60.

GLIESSMAN, S. R. Agroecologia: processos ecológicos em agricultura sustentável. Porto Alegre: Editora - UFRGS, 2000.

\section{INSTITUTO BRASILEIRO DE GEOGRAFIA E ESTATÍSTICA (IBGE). Pesquisa}

Nacional de Saneamento Básico. 2008. Disponível em: < http://www.ibge.gov.br/home/presidencia/ noticias/noticia_visualiza.php?id_noticia $=1691 \&$ id

_pagina=1> Acesso em 16 jan. 2014.

LAYRARGUES, P. P. (Coord.). Identidades da Educação Ambiental Brasileira. Brasília: Ministério do Meio Ambiente, 2004.

LELIS, J. L.; LOBO, L. M.; MUGGLER, C. C.; CAON, K. G.; CAMPOS, J. L. de A.; PEREIRA, D. M.; VILLAR, J. P.; MORAIS, E. H. M.; PRIMO, F.
Discutindo o solo na escola: construção de conceitos e valores ambientais. Revista Brasileira de Agroecologia, v.2, n.2, p. 559-562, 2007.

MORGENSTERN, L. T. B., FRANCISCHETT, M. N. Educação ambiental: uma proposta interdisciplinar. Santa Terezinha de Itaipu-PR, 2008, p.22.

ONU. Conferência das Nações Unidas Sobre Meio Ambiente e Desenvolvimento. Agenda 21. Promoção do Ensino, da Conscientização e do Treinamento. Capítulo 36. 1992.

PEREIRA, J. S. Educação ambiental na educação infantil - um compromisso social. Revista Brasileira de Agroecologia, v.2, n.1, p.4, 2007.

PEREIRA NETO, J.T.; Manual de compostagem: Processo de baixo custo. Viçosa, ed. UFV, 2007.

QUEIROZ, S. T., LIMA, A. G., OLIVEIRA, G. Reciclagem e Reaproveitamento de resíduos sólidos e Educação Ambiental: Um relato de oficinas pedagógicas, 2008.

REIGOTA, M. O que é educação ambiental 1. ed. São Paulo: Editora Brasiliense, 1994.

ROSA, B. N., MORAES, G. G. MAROÇO, M., CASTRO, R. A importância da reciclagem do papel na melhoria da qualidade do meio ambiente. In: XXV Encontro Nacional de Engenharia de Produção (ENEGEP), Porto Alegre/RS, 2005.

SANTOS, E. T. A. Educação ambiental na escola: conscientização da necessidade de proteção da camada de ozônio. 2007. 51 f. Monografia (Especialização em Educação Ambiental) Universidade Federal de Santa Maria, Santa Maria, 2007.

SARAIVA, V. M.; NASCIMENTO, K. R. P.; COSTA, R. K. M. A prática pedagógica do ensino de educação ambiental nas escolas públicas de João Câmara - RN. Revista Holos, n. 24, v. 2, p. 81-93, 2008.

SILVA, R. V., RAUBER, S. C., EICKHOFF, A. P. N., BARBOSA, I. G., NETO, G. G. Educação ambiental em espaços escolarizados: um estudo de caso na escola municipal Santos Dumont, Cáceres-MT. Revista eletrônica Mestrado Educação Ambiental, v. 26, p. 14, 2011. 
SILVA, A. G.; CAVAlCANTE, A. C. P.; SILVA, M. J. R.; Educação ambiental nas escolas como instrumento para reciclagem dos resíduos sólidos. In: II seminário piauiense de agroecologia. Esperantina, Piauí, 2012.

SOARES, L. G. C., SALGUEIRO, A. A., GAZINEU, M. H. P. Educação ambiental aplicada aos resíduos sólidos na cidade de Olinda, Pernambuco - um estudo de caso. Revista Ciências \&

Tecnologia, Ano 1, n. 1, 2007. 